\title{
Transoral-Transpalatal Approach and Endoscopic Endonasal Approach for Chordomas of the Craniovertebral Junction
}

\author{
Satoka Shidoh $^{1 *}$, Masahiro Toda ${ }^{1}$, Hideo Nakajima ${ }^{2}$, Toshiki Tomita ${ }^{3}$, Kaoru Ogawa ${ }^{3}$, Takeshi Kawase ${ }^{1}$ and Kazunari Yoshida ${ }^{1}$ \\ ${ }^{1}$ Department of Neurosurgery, Keio University School of Medicine, Tokyo, Japan \\ ${ }^{2}$ Department of Plastic Surgery, Keio University School of Medicine, Tokyo, Japan \\ ${ }^{3}$ Department of Otolaryngology, Keio University School of Medicine, Tokyo, Japan
}

\begin{abstract}
Chordomas are tumors arising from notochord remnants, which are often located in midline skull base structures such as the clivus. The location of the tumor can extend to the craniocervical junction, which can increase the difficulty in reaching the tumor. The recently developed endonasal endoscopic approach has allows access to the entire ventral skull base lesion directly. However, it is still difficult to access lesions around the craniovertebral junction. The transoral-transpalatal approach allows a surgical field up to the upper clivus by removing the hard palate down to the C3 level. Although the endonasal endoscopic approach is a useful surgical technique for clival lesions, we should consider using the transoral/transoral-transpalatal approach for lesions between the craniovertebral junction and the C3 level.
\end{abstract}

Keywords: Chordoma; Transoral-transpalatal approach; Endonasal endoscopic approach; Craniovertebral junction

Abbreviations: CVJ: Craniovertebral Junction; EEA: Endoscopic Endonasal Approach

\section{Introduction}

Chordomas often arise from the midline clivus and extend bidirectional into the nasopharynx, intracranium, CVJ, and upper cervical area. To achieve longer survival rates, the first choice of treatment for this type of epidural tumor is complete surgical removal because of their high recurrence rates [1-6]. Nevertheless, it is difficult to achieve complete removal because of their extensiveness and invasiveness. When removing this type of tumor, it is important to consider the location of the tumor origin, which is typically, the midline of the bone structure. Operative procedures should be performed in the extradural space as much as possible, and we must choose the most appropriate operative approach, which should be based on the direction of tumor progression. Such considerations are important for both maintaining the patient's activities of daily living, and aiming for maximum resection of the tumor.

The endoscopic endonasal approach (EEA) was developed to remove pituitary adenomas or intrasellar craniopharyngiomas. Modification of this procedure could provide an extended surgical field, including the skull base from the frontal sinus to the C1body, and allow access to skull base tumors such as meningiomas and chordomas [7-15]. This approach also has the advantage of minimal invasiveness to neurovascular structures [16].

Arana-Iniguez $\mathrm{R}$ et al. [17] reported the transoral approach for clival and high cervical chordomas in 1968. The transoral-transpalatal approach, which consists of splitting the soft palate and partial removal of the hard palate, has been developed for tumors around the foramen magnum $[18,19]$. Alonso applied this approach to a clivalchordoma for the first time in 1971 [20]. Since then, various transoral-transpalatal approaches have been reported that allow access to the lower clivus up to the C2 vertebral body [21-25]. We modified this approach and extended the surgical field to the upper limit of the entire sellar region by widely resecting hard palate bone. Seker et al . [26] reported a comparison between EEA and the transoral approach to the craniovertebral junction (CVJ) by cadaveric crania. Both techniques provided direct access to the CVJ, however, EEA had an advantage with a shorter route for CVJ, whereas the transoral approach provided as wider surgical field. Although EEA has an advantage in its minimal invasiveness, the transoral-transpalatal approach is still useful for chordomas based on their location. The present study reviews our experience with chordomas over the previous 10 years, and consider the applications of the transoral-transpalatal approach and EEA.

\section{Operative Procedures and Representative Cases}

\section{Endoscopic endonasal approach}

A straight 4-mm endoscope and angled scope were used. The right middle turbinate was removed and a vascularized nasoseptal flap was formed. The posterior part of the nasal septum was resected for the binostril approach. The sphenoid sinus floor was drilled to the nasopharynx and the clivus and bone over the sella was removed if the tumor extended into the cavernous sinus. If the tumor invaded the subdural space, we used forehand endoscopic techniques with a wider surgical field. Reconstruction was performed with the fascia at the subdural space and the pedicled nasoseptal flap over the fascia. Oxidized cellulose with fibrin glue was used at the bone edge. A 14-F Foley catheter provided pressure and supported the multilayer reconstruction. The catheter was removed 3-4 days after the operation [27].

EEA was used for treating a 68-year-old man who complained of diplopia for at least 1year. Left VI paresis and binasal hemianopsia were observed at the outpatient clinic. Magnetic resonance imaging showed

*Corresponding author: SatokaShidoh, Department of Neurosurgery, Keio University School of Medicine, 35 Shinanomachi, Shinjuku-ku, Tokyo 160-8582, Japan, Tel: +81 3-5363-3808; Fax: +81-3-3354-8053; E-mail: blsk_sl_satok@z2.keio.jp

Received July 26, 2013; Accepted August 30, 2013; Published September 10 2013

Citation: Shidoh S, Toda M, Nakajima H, Tomita T, Ogawa K, et al. (2013) TransoralTranspalatal Approach and Endoscopic Endonasal Approach for Chordomas of the Craniovertebral Junction. J Neurol Neurophysiol 4: 162. doi:10.4172/21559562.1000162

Copyright: $\odot 2013$ Shidoh S, et al. This is an open-access article distributed unde the terms of the Creative Commons Attribution License, which permits unrestricted use, distribution, and reproduction in any medium, provided the original author and source are credited. 
Citation: Shidoh S, Toda M, Nakajima H, Tomita T, Ogawa K, et al. (2013) Transoral-Transpalatal Approach and Endoscopic Endonasal Approach for Chordomas of the Craniovertebral Junction. J Neurol Neurophysiol 4: 162. doi:10.4172/2155-9562.1000162

a tumor in the skull base extending from the sella to mid-clivus (Figure 1A). Operation with EEA was performed and gross total removal was achieved (Figure 1B).

\section{Transoral-transpalatal approach}

Our modified method for the transoral-transpalatal approach is presented below.

The midline of the gingivobuccal sulcus first was incised for about $1 \mathrm{~cm}$, the anterior nasal spine was exposed under the periosteum, and the nasal floor was dissected. Then, a vomer osteotomy was performed. A Crockard retractor was applied until the mouth was fully opened.

A U-shaped mucosal incision was made along the maxillary alveolar process up to the second/third molars. The midline was then incised along the palatine raphe from the incisive foramen toward the uvula, and passing by the uvula. Bilateral mucoperiosteal flaps were raised as an island flaps with the great palatine vessel as its pedicle. The whole hard palatal bone was then exposed and punctures were made with a drill along the maxillary alveolar process, followed by cutting with a chisel. The horseshoe-shaped bony hard palate was resected as far as possible. The excised bone had a ridge in the center. As the mucosa of the nasal floor appeared, a vertical incision was made unilaterally or bilaterally, which revealed the upper clivus. If the perioperative visualization was obstructed by the inferior concha or nasal septum, these were resected.

A straight or S-shaped pharyngeal incision was made and the tumor was removed. In patients with dural hole, a free piece of abdominal fascia was placed and fixed with fibrin glue. The incised nasal floor was sutured, and the hard palate bone, which was temporarily excised, was returned to the original site. There was no need for bone fixation. The soft palate was sutured in three layers: the muscular layer and, the two mucosal layers of both the nasal and oral cavities. The mucoperiosteal flap of the hard palate was sutured as one layer. Tube feeding was provided for about 1 week after operation, followed by transoral intake whenever possible.

The transoral-transpalatal approach was used for treating a 72-yearold woman who complained of snoring and numbness along the front of her neck. She visited an ENT department at a nearby hospital.
Computed tomography showed a mass in her retropharyngeal space at the $\mathrm{C} 2$ level and she was referred to the orthopedics department. She underwent biopsy and the pathological diagnosis was chordoma. Two years later, she complained of numbness and weakness in the right upper extremity. She was referred to us and a C1-C3 half laminectomy was performed. After the first operation, she underwent heavy corpuscular ray for residual tumor. Six years later, the residual tumor had enlarged (Figure 2A) and she underwent tumor removal with the transoral-transpalatal approach. (Figure 2B) Currently, 2years after the second operation, she is being followed up at an outpatient clinic, and has had no recurrence.

\section{Discussion}

The transoral-transpalatal approach provides a wide surgical field in the CVJ and clivus. The introduction of EEA has rendered the operative procedures for these areas into minimally invasive tools. EEA provides access upward from the $\mathrm{C} 1$ level to the anterior skull base [7-15], and is, an alternative method to transcranial approaches with minimal morbidity [28,29]. Table 1 shows operative cases of chordomas in our institution over the previous 10 years, and the ratio of EEA cases. We founded a EEA team with otolaryngology in 2009. Since then, operations involving the transnasal approach are performed by EEA. Between 2002 and 2008, the ratio for the transnasal approach per total surgical cases was 15\%, and between 2009 and 2012, the ratio of transnasal approach (EEA) cases was $42 \%$. The ratio of transoraltranspalatal approach cases per total surgical cases was $15 \%$ before EEA started. Over the previous 3 years, the ratio has decreased to $7.7 \%$. Although this change has occurred, the transoral-transpalatal approach still has the advantage of a wider surgical field that is not disturbed by the nasal septum, and reduced injury to the petrous carotid artery [26]. When choosing an approach for chordomas, the difference between the transoral approach and EEA is the accessing angle and the width of the operative field. EEA is limited in accessing the inferior part by the nasal cartilage anteriorly, and by the hard and soft palate posteriorly. Furthermore, there is limited exposure of the $\mathrm{C} 2$ body below the odontoid process near the hard palate [26]. The transoral-transpalatal approach is much easier to access between $\mathrm{C} 1$ and $\mathrm{C} 3$ regions, and by removing the hard palate, access can be gained to the upper clivus [Figure 3]. Combination of the transoral approach and the EEA is also considered for large tumors extending below the $\mathrm{C} 2$ body.

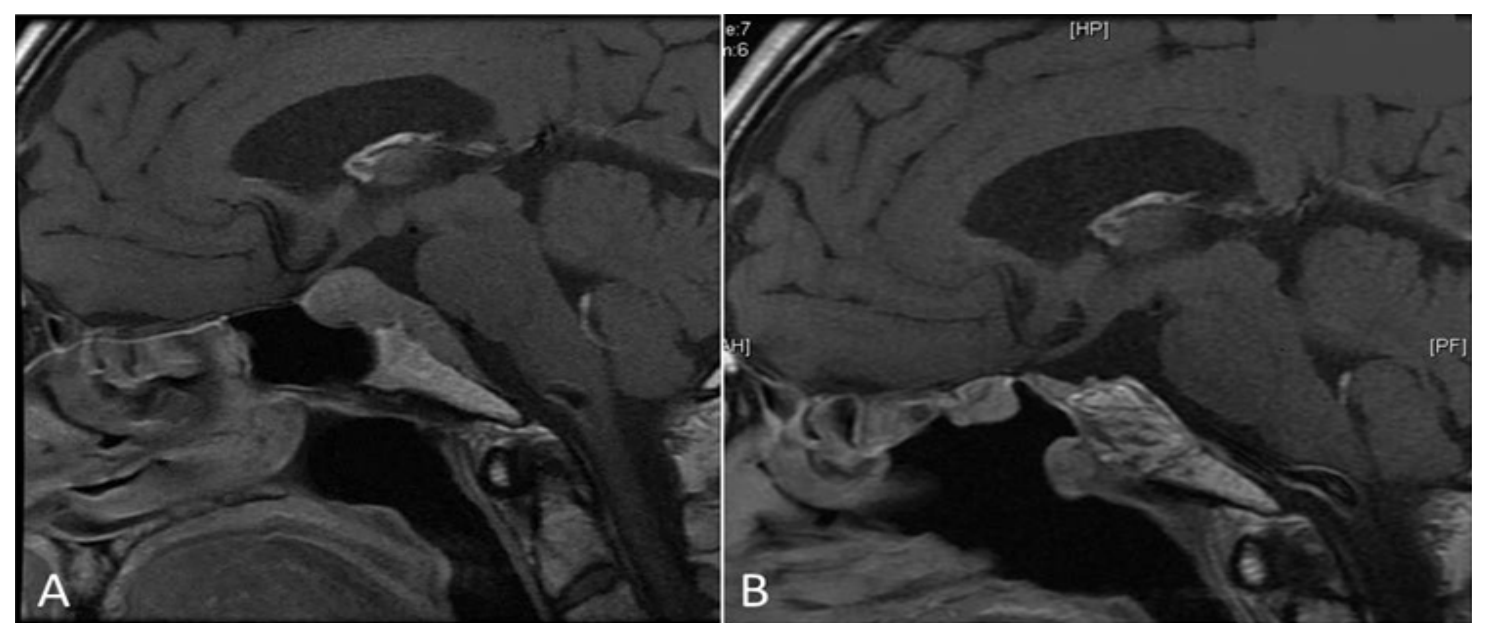

Figure 1: Representative radiological findings of an endonasal endoscopic approach (EEA) case. Sagittal section of MRI(Gd-T1WI).

A. Preoperative image shows the tumor, which was located in the sella and mid-clivus.

B. Postoperative image shows the tumor was removed and replaced with the nasoseptal flap. 
Citation: Shidoh S, Toda M, Nakajima H, Tomita T, Ogawa K, et al. (2013) Transoral-Transpalatal Approach and Endoscopic Endonasal Approach for Chordomas of the Craniovertebral Junction. J Neurol Neurophysiol 4: 162. doi:10.4172/2155-9562.1000162

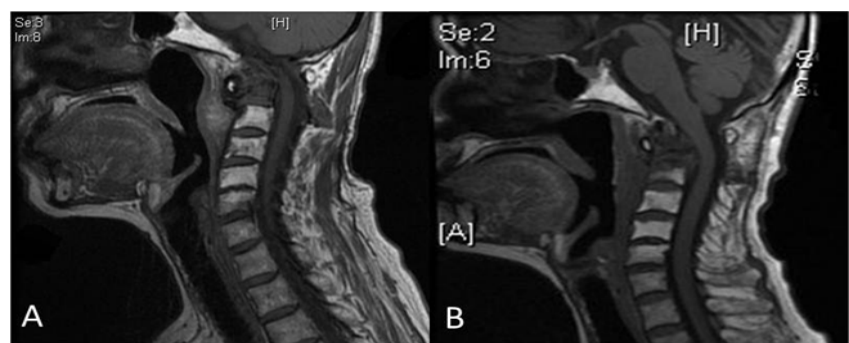

Figure 2: Representative radiological findings of a transoral-transpalatal case. Sagital section of MRI (Gd-T1WI).

A. Preoperative image shows the tumor located in the retropharyngeal area at theC2 level and extends below to the C3 body.

B. Postoperative image shows no residual tumor.

\begin{tabular}{|c|c|c|c|c|}
\hline Approach & & $\mathbf{2 0 0 2 - 2 0 0 8}$ & $\mathbf{2 0 0 9 - 2 0 1 2}$ \\
\hline Anterior & & Transnasal & 9 & 9 \\
\hline & & Trasoral-transpalatal & 9 & 2 \\
\hline & & Trans Maxillar & 1 & 0 \\
\hline Lateral Middle fossa & & Others & 7 & 2 \\
\hline & & transpetrosal & 15 & 2 \\
\hline Pubtemporal & 5 & 7 \\
\hline Posterior fossa & & $\begin{array}{c}\text { Others } \\
\text { transjugular/ } \\
\text { transcondylar }\end{array}$ & 1 & 0 \\
\hline Total & 86 & 13 & 4 \\
\hline
\end{tabular}

Table 1: All chordoma cases over the previous 10 years (2002-2012) in our institution were analyzed with this approach. Between 2009 and 2012, all transnasal cases were treated with EEA.

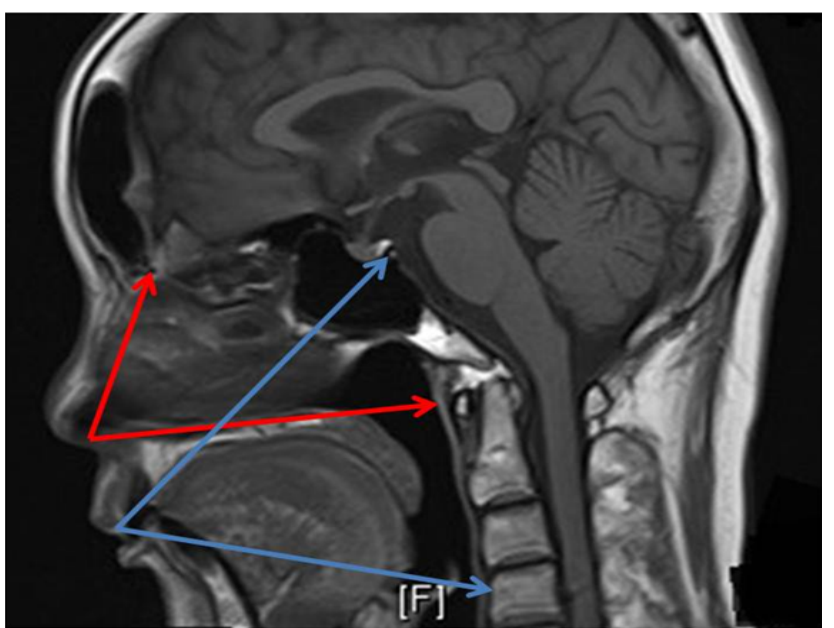

Figure 3: Difference in surgical field and angle of the EEA (red arrow) and transoral-transpalatal approach(blue arrow).

\section{Conclusion}

EEA is a less invasive and useful surgical method for clival chordomas. However, when the tumor is located around the craniocervical junction, EEA is limited in its surgical operability and the transoral-transpalatal approach should be considered.

\section{References}

1. Crockard HA, Steel T, Plowman N, Singh A, Crossman J, et al. (2001) A multidisciplinary team approach to skull base chordomas. J Neurosurg 95: 175183.
2. Dehdashti AR, Gentili F (2007) Current state of the art in the diagnosis and surgical treatment of Cushing disease: early experience with a purely endoscopic endonasal technique. Neurosurg Focus 23: E9.

3. Sen C, Triana Al, Berglind N, Godbold J, Shrivastava RK (2010) Cliva chordomas: clinical management, results, and complications in 71 patients. J Neurosurg 113: 1059-1071.

4. Colli B, Al-Mefty O (2001) Chordomas of the craniocervical junction: follow-up review and prognostic factors. J Neurosurg 95: 933-943.

5. Gay E, Sekhar LN, Rubinstein E, Wright DC, Sen C, et al. (1995) Chordomas and chondrosarcomas of the cranial base: results and follow-up of 60 patients. Neurosurgery 36: 887-896.

6. Tzortzidis F, Elahi F, Wright D, Natarajan SK, Sekhar LN (2006) Patient outcome at long-term follow-up after aggressive microsurgical resection of cranial base chordomas. Neurosurgery 59: 230-237.

7. Ogawa $\mathrm{Y}$, Tominaga $\mathrm{T}$ (2012) Extended transsphenoidal approach fo tuberculum sellae meningioma--what are the optimum and critical indications? Acta Neurochir (Wien) 154: 621-626.

8. Couldwell WT, Weiss MH, Rabb C, Liu JK, Apfelbaum RI, et al. (2004) Variations on the standard transsphenoidal approach to the sellar region, with emphasis on the extended approaches and parasellar approaches: surgical experience in 105 cases. Neurosurgery 55: 539-547.

9. de Divitiis E, Cappabianca P, Cavallo LM (2002) Endoscopic transsphenoida approach: adaptability of the procedure to different sellar lesions. Neurosurgery 51: 699-705.

10. Dusick JR, Esposito F, Kelly DF, Cohan P, DeSalles A, et al. (2005) The extended direct endonasal transsphenoidal approach for nonadenomatous suprasellar tumors. J Neurosurg 102: 832-841.

11. Kaptain GJ, Vincent DA, Sheehan JP, Laws ER Jr (2001) Transsphenoidal approaches for the extracapsular resection of midline suprasellar and anterior cranial vase lesions. Neurosurgery 49: 94-101.

12. Kassam A, Snyderman CH, Mintz A, Gardner P, Carrau RL (2005) Expanded endonasal approach: the rostrocaudalaxix Part I. Crista galli to the sellarturnica. Neurosurg Focus 19:E3.

13. Kassam A, Snyderman CH, Mintz A, Gardner P, Carrau RL (2005) Expanded endonasal approach: the rostrocaudal axis. Part II. Posterior clinoids to the foramen magnum. Neurosurg Focus 19: E4.

14. Kassam AB, Gardner P, Snyderman C, Mintz A, Carrau R (2005) Expanded endonasal approach: fully endoscopic, completely transnasal approach to the middle third of the clivus, petrous bone, middle cranial fossa, and infratemporal fossa. Neurosurg Focus 19: E6.

15. Kassam AB, Snyderman C, Gardner P, Carrau R, Spiro R (2005) The expanded endonasal approach: a fully endoscopic transnasal approach and resection of the odontoid process: technical case report. Neurosurgery 57: E213.

16. Prosser JD, Vender JR, Alleyne CH, Solares CA (2012) Expanded endoscopic endonasal approaches to skull base meningiomas. J Neurol Surg B Skull Base 73: 147-156.

17. Arana-Iñiguez R, Castillo LA, Benedek P, Folle JA (1968) Transoral approach in clivus and high cervical chordomas. Acta Neurol Latinoam 14: 65-73.

18. Dibble PA, King HC (1962) Juvenile nasopharyngeal angiofibroma Laryngoscope 72: 218-231.

19. Mullan S, Naunton R, Hekmat-Panah J, Vailati G (1966) The use of an anterio approach to ventrally placed tumors in the foramen magnum and vertebra column. J Neurosurg 24: 536-543.

20. Alonso WA, Black P, Connor GH, Uematsu S (1971) Transoral transpalatal approach for resection of clival chordoma. Laryngoscope 81: 1626-1631.

21. Biller HF, Shugar JM, Krespi YP (1981) A new technique for wide-field exposure of the base of the skull. Arch Otolaryngol 107: 698-702.

22. Mattox DE, Carson BS (1991) Transpalatal transsphenoidal approach to the sella in children. Skull Base Surg 1: 177-182.

23. Menezes AH (2008) Surgical approaches: postoperative care and complication "transoral-transpalatopharyngeal approach to the craniocervical junction". Childs Nerv Syst 24: 1187-1193.

24. Dubey SP, Molumi CP (2012) Transpalatal approach with pedicled palata osteo-muco-periosteal flap. ANZ J Surg 82: 439-442. 
Citation: Shidoh S, Toda M, Nakajima H, Tomita T, Ogawa K, et al. (2013) Transoral-Transpalatal Approach and Endoscopic Endonasal Approach for Chordomas of the Craniovertebral Junction. J Neurol Neurophysiol 4: 162. doi:10.4172/2155-9562.1000162

Page 4 of 4

25. Liu JK, Couldwell WT, Apfelbaum RI (2008) Transoral approach and extended modifications for lesions of the ventral foramen magnum and craniovertebral junction. Skull Base 18: 151-166.

26. Seker A, Inoue K, Osawa S, Akakin A, Kilic T, et al. (2010) Comparison of endoscopic transnasal and transoral approaches to the craniovertebral junction. World Neurosurg 74: 583-602.

27. Saito K, Toda M, Tomita T, Ogawa K, Yoshida K (2012) Surgical results of an endoscopic endonasal approach for clival chordomas. Acta Neurochir (Wien) 154: $879-886$

28. Koutourousiou M, Gardner PA, Tormenti MJ, Henry SL, Stefko ST, et al. (2012) Endoscopic endonasal approach for resection of cranial base chordomas: outcomes and learning curve. Neurosurgery 71: 614-624.

29. Hwang PY, Ho CL (2007) Neuronavigation using an image-guided endoscopic transnasal-sphenoethmoidal approach to clival chordomas. Neurosurgery 61 : 212-217. 